\title{
Um levantamento de teses e dissertações de um programa de pós-graduação sobre a aproximação da História da Ciência e o Ensino de Ciências
}

Lorena Cristina Romero Palma

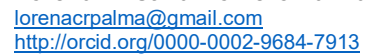
http://orcid.org/0000-0002-9684-7913 Mesquita Filho" (Unesp), Bauru, São Paulo, Brasil

Patricia Vecchio Guarnieri patyvecchio@gmail.com http://orcid.org/0000-0002-4443-6792 Universidade Estadual Paulista "Júlio de Mesquita Filho" (Unesp), Bauru, São Paulo, Brasil

Fernanda Cristina Pansera fernandacpansera@gmail.com http://orcid.org/0000-0001-5619-9723 Universidade Estadual Paulista "Júlio de Mesquita Filho" (Unesp), Bauru, São Paulo, Brasil

Sandra Regina Teodoro Gatti

sandragatti@gmail.com Universidade Estadual Paulista "Júlio de Mesquita Filu" (Una Paulsta "Júlio de Paulo, Brasil

\section{RESUMO}

Considerando a importância da aproximação da História da Ciência (HC) com o Ensino de Ciências, buscou-se desenvolver uma pesquisa com o objetivo de elaborar um panorama de teses e dissertações produzidas no Programa de Pós-Graduação Interunidades em Ensino de Ciências - USP, de 2012 a 2016, e que abordam a HC no Ensino de Ciências. Fez-se uma busca na Biblioteca Digital de Teses e Dissertações da USP, procurando evidenciar o total de trabalhos defendidos no programa desde a sua implementação e em relação aos anos de 2012 a 2016. No que diz respeito aos cinco anos mencionados, foram defendidos 220 trabalhos. Levantou-se aqueles trabalhos que utilizaram a abordagem de $\mathrm{HC}$, sendo um total de 23. A fim de identificar quais as perspectivas de HC utilizadas por tais trabalhos, buscou-se evidenciar quais os objetivos e focos das teses e dissertações selecionadas. Encontrou-se cinco categorias de trabalhos, utilizando as categorias propostas por Morais (2016), sendo História da Ciência no Ensino de Ciências a mais significante em números de trabalhos. Com a realização desse levantamento nota-se a necessidade de dar atenção a trabalhos que versem sobre a $\mathrm{HC}$, devido ao fato de inferir-se que a sua utilização na prática docente auxilia em uma visão de Ciência mais adequada, que possibilita questionamentos e não a aceitação desta como uma verdade absoluta, contribuindo para a formação do estudante.

PALAVRAS-CHAVE: História da Ciência. Levantamento. Teses e Dissertações. Ensino de Ciências. 


\section{INTRODUÇÃO}

A presente pesquisa foi desenvolvida considerando a relevância da HC no Ensino de Ciências, cuja importância é ressaltada nos trabalhos de Matthews (1995) e de Gil-Pérez et al. (2001), por meio de uma abordagem de Ciência pautada em uma visão crítica e não linear, que possibilite a compreensão da sua construção. Nesse sentido, o recorte realizado neste trabalho analisa as pesquisas defendidas no âmbito do Programa de Pós-Graduação Interunidades em Ensino de Ciências da Universidade de São Paulo (USP), por ser um programa de grande reconhecimento na área e possuir uma linha de pesquisa relacionada à $\mathrm{HC}$.

Diante disso, foi desenvolvida uma pesquisa de "estado do conhecimento"1, na qual objetivou-se fazer um mapeamento dos trabalhos sobre HC, produzidos entre 2012 e 2016, no programa supracitado, por meio de consulta na Biblioteca Digital de Teses e Dissertações da USP².

As abordagens, os enfoques e os objetivos das dissertações e teses são diversos. É importante destacar que este trabalho não tem o objetivo de apresentar cada uma das pesquisas, mas sim fazer um panorama geral do que está sendo produzido no Programa, assumindo assim que para a compreensão e descrição das especificidades de cada pesquisa é fundamental a leitura integral dos trabalhos.

As autoras apresentam neste artigo alguns dados referentes ao contexto geral do Programa, a metodologia empregada na pesquisa, os resultados quantitativos do levantamento, bem como uma breve descrição dos trabalhos, visando contribuir para o reconhecimento da relevância das pesquisas desenvolvidas na área de Ensino de Ciências sobre a HC.

\section{O CONTEXTO DA PESQUISA}

O Programa de Pós-Graduação Interunidades em Ensino de Ciências da Universidade de São Paulo (USP) foi criado em 1973, é reconhecido como o primeiro curso de pós-graduação na área de Ensino de Ciências no Brasil (NARDI, 2005). A pós-graduação (stricto sensu) foi fundada pelo Instituto de Física (IF-USP, outrora Departamento de Física) em parceria com a Faculdade de Educação da Universidade de São Paulo (FEUSP), motivo pelo qual é chamado Interunidades. Ainda de acordo com a pesquisa de Nardi (2005), o surgimento do programa está relacionado principalmente a três fatores, são eles: organização de um grupo de docentes preocupados com a melhoria do Ensino de Física; estudos relacionados à avaliação de projetos estrangeiros para o Ensino; criação e implantação de projetos brasileiros de ensino adaptados à realidade do país.

Em 1998, o Instituto de Química passou a integrar a pós-graduação Interunidades em Ensino de Ciências e mais recentemente, em 2005 o Instituto de Biociências também se integrou ao programa. Atualmente o programa oferece os cursos de mestrado e de doutorado com dois objetivos principais: produzir conhecimento em educação científica nas áreas de Física, Química e Biologia; e formar pesquisadores de alta qualidade na área de Ensino de Ciências (NARDI, 2005). 
O Programa é reconhecido nacionalmente pela qualidade dos trabalhos produzidos. A última avaliação realizada pela Capes (Coordenadoria de Aperfeiçoamento de Pessoal de Nível Superior) atribuiu a nota 5, ou seja, ele está entre os melhores programas da área de Ensino de Ciências ${ }^{3}$ do país.

A pós-graduação Interunidades em Ensino de Ciências conta com a colaboração de 51 professores credenciados que ministram aulas e orientam pesquisas com os mais variados enfoques. O Programa define cinco linhas de pesquisa as quais os estudos geralmente estão envolvidos. Vale ressaltar que 42 docentes estão vinculados a uma ou mais linhas de pesquisa. Outros nove docentes orientam trabalhos em áreas específicas, como por exemplo, inclusão e neurociência no ensino, e esses professores não estão vinculados a nenhuma das linhas de pesquisa. No Quadro 1 são apresentadas as linhas de pesquisa, suas descrições e o número de docentes ligados a cada uma delas.

Quadro 1 - Número de docentes e descrição das linhas de pesquisa do programa de pósgraduação Interunidades em Ensino de Ciências da USP

\begin{tabular}{|c|c|c|}
\hline $\begin{array}{l}\text { Linha de } \\
\text { pesquisa }\end{array}$ & Descrição & $\begin{array}{c}\text { Número } \\
\text { de } \\
\text { docentes } \\
\end{array}$ \\
\hline $\begin{array}{c}\text { L1 - Recursos } \\
\text { Didáticos para o } \\
\text { Ensino de Ciências }\end{array}$ & $\begin{array}{l}\text { Estudo da natureza, do conteúdo e da linguagem de } \\
\text { diferentes meios como experimentos, atividades } \\
\text { lúdicas, computadores, vídeos, filmes, etc. e o papel } \\
\text { dos mesmos no processo ensino-aprendizagem. }\end{array}$ & 23 \\
\hline $\begin{array}{l}\text { L2 - História, } \\
\text { Filosofia e Cultura } \\
\text { no Ensino de } \\
\text { Ciências }\end{array}$ & $\begin{array}{l}\text { Investigações relativas a aspectos históricos, } \\
\text { filosóficos ou sociológicos da ciência (Física, Química } \\
\text { e Biologia), bem como das relações entre ciência e } \\
\text { cultura, e suas implicações no ensino de Ciências } \\
\text { (Física, Química e Biologia) em diferentes níveis ou } \\
\text { abordagens. }\end{array}$ & 16 \\
\hline $\begin{array}{l}\text { L3 - Ensino- } \\
\text { Aprendizagem de } \\
\text { Ciências }\end{array}$ & $\begin{array}{c}\text { Estudos que abordam aspectos do processo de } \\
\text { ensino-aprendizagem relativos à construção do } \\
\text { conhecimento e à formação conceitual em Física, } \\
\text { Química e Biologia. Ou seja, que tratam das } \\
\text { concepções conceituais dos estudantes, modelos, } \\
\text { propostas e diagnósticos de aprendizagem; da } \\
\text { avaliação e de aspectos linguísticos na formação } \\
\text { conceitual ou nos discursos de estudantes e } \\
\text { professores. }\end{array}$ & 32 \\
\hline $\begin{array}{l}\text { L4 - Formação de } \\
\text { Professores }\end{array}$ & $\begin{array}{c}\text { Investigações sobre formação inicial ou continuada } \\
\text { de professores de ciências, para os diferentes níveis } \\
\text { de ensino, incluindo programas de aperfeiçoamento } \\
\text { de professores, avaliação de práticas pedagógicas e } \\
\text { de cursos e programas específicos das licenciaturas } \\
\text { ou magistério. }\end{array}$ & 21 \\
\hline
\end{tabular}




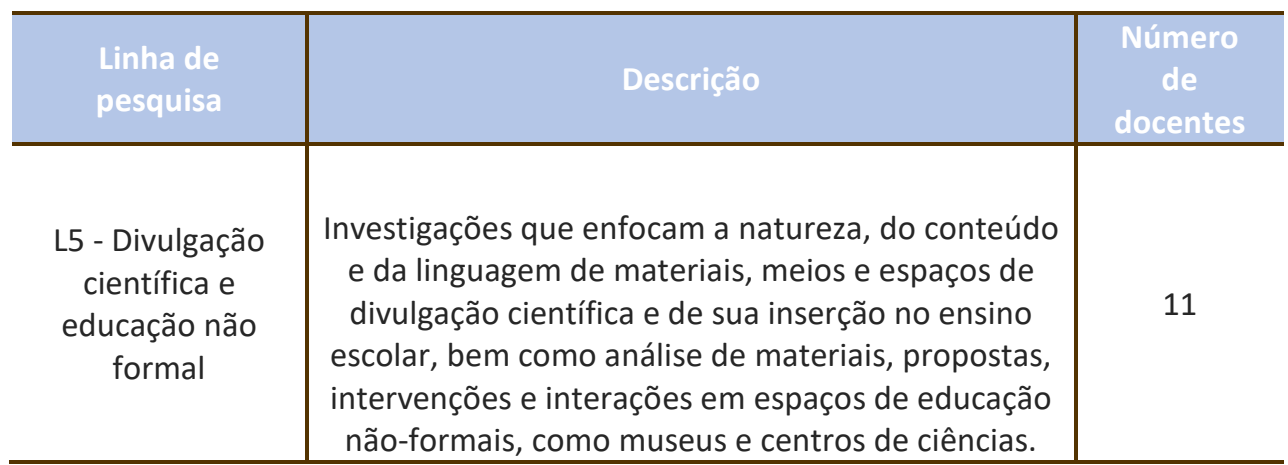

Fonte: Adaptado do site da pós-graduação Interunidades em Ensino de Ciências. Acesso em 01 de maio de 2017.

\title{
FUNDAMENTAÇÃO TEÓRICA
}

Historicamente, a preocupação com o Ensino de Ciências no contexto brasileiro vem crescendo desde a década de 1950 (KRASILCHIK, 2000). Um dos aspectos que está sendo discutido cada vez mais se refere a inserção da $\mathrm{HC}$ no Ensino (MARTORANO, 2012).

Dessa forma, de acordo com Matthews (1995) a inserção da História e Filosofia da Ciência (HFC) no Ensino de Ciências poderia,

\begin{abstract}
[...] humanizar as ciências e aproximá-las dos interesses pessoais, éticos, culturais e políticos da comunidade; podem tomar as aulas de ciências mais desafiadoras e reflexivas, permitindo, deste modo, o desenvolvimento do pensamento crítico; podem contribuir para um entendimento mais integral de matéria científica, isto é, podem contribuir para a superação do "mar de falta de significação" que se diz ter inundado as salas de aula de ciências, onde fórmulas e equações são recitadas sem que muitos cheguem a saber o que significam; podem melhorar a formação do professor auxiliando o desenvolvimento de uma epistemologia da ciência mais rica e mais autêntica, ou seja, de uma maior compreensão da estrutura das ciências bem como do espaço que ocupam no sistema intelectual das coisas (MATTHEWS, 1995, p.165).
\end{abstract}

Ao inserir HC nas escolas, é possível desenvolver uma nova visão de ciência, capaz de aproximar o estudante ao meio científico, mostrando o caráter humano e real no qual a ciência é produzida. Significa trabalhar as ciências além do conteúdo formal, abordando a história e o contexto no qual aqueles cientistas estavam quando produziram determinado conhecimento. Além de auxiliar na construção da prática docente, proporcionando ao professor uma visão mais adequada de Natureza da Ciência ( $\mathrm{NdC}$ ).

Contudo, tem-se que a inserção de estudos de $\mathrm{HC}$ nas escolas, ainda enfrenta muitos desafios, embora os professores, em sua maioria, reconheçam a importância de ensiná-la, poucos são os que possuem conhecimentos adequados sobre a HC e NdC (MARTORANO, 2012).

A Ciência consiste em uma atividade de estudo e compressão dos mais diversos temas. Suas ideias e conceitos encontram-se abertos e em constante mudança. Muitos professores ainda possuem visões: empírico-indutivista; aproblemática e ahistórica; cumulativa e de crescimento linear; individualista e elitista, além de uma visão descontextualizada da Ciência (GIL-PÉREZ et al., 2001). 
Outro aspecto, apontado por Santos e Mortimer (2002, p. 5) diz respeito aos interesses por trás da ciência, destacando que as visões mais críticas "têm buscado desfazer o mito do cientificismo que ideologicamente ajudou a consolidar a submissão da ciência aos interesses de mercado, à busca do lucro".

Conforme Beltran (2013) destacou em sua pesquisa, ainda são poucos os trabalhos que conseguem fazer a interface da HC com o Ensino de Ciências, é preciso investir esforços em pesquisas que abordem questões sobre a $\mathrm{HC}$ na formação inicial e continuada dos professores de ciências, assim como a sua presença na Educação Básica.

Por esses motivos, torna-se importante conhecer o que vem sendo produzido nas pesquisas da área de Ensino de Ciências, possibilitando dessa forma discussões cada vez mais coerentes, contribuindo para a solidificação da HC como linha de pesquisa de fundamental importância para a melhoria do ensino nos mais diferentes níveis de formação (ROMANOWSKI; ENS, 2006).

\section{METODOLOGIA}

Diante dos objetivos do trabalho, realizou-se uma busca na Biblioteca Digital de Teses e Dissertações da USP, a fim de selecionar os trabalhos defendidos no Programa de Pós-Graduação Interunidades em Ensino de Ciências da USP, que envolvem a HC nos anos de 2012 a 2016.

Além disso, buscou-se a quantidade de teses e dissertações já defendidas no referido programa. Para tal, no site da biblioteca digital, na aba Unidades, procurou-se por "Interunidades em Ensino de Ciências". O próprio site forneceu um quadro contendo as informações sobre quantos trabalhos foram defendidos por área de conhecimento desde o início do programa. O Quadro 2 apresenta uma adaptação do quadro fornecido pelo site.

Quadro 2 - Número de documentos por área de conhecimento

\begin{tabular}{c|c|c|c}
\hline $\begin{array}{c}\text { Área do } \\
\text { conhecimento }\end{array}$ & $\begin{array}{c}\text { Dissertação de } \\
\text { Mestrado }\end{array}$ & $\begin{array}{c}\text { Tese de } \\
\text { Doutorado }\end{array}$ & $\begin{array}{c}\text { Tese de Livre } \\
\text { docência }\end{array}$ \\
\hline Ensino de Biologia & 61 & 0 & 0 \\
\hline Ensino de Física & 104 & 50 & 0 \\
\hline $\begin{array}{c}\text { Ensino de Química } \\
\text { Modalidade } \\
\text { Biologia }\end{array}$ & 168 & 0 & 0 \\
\hline $\begin{array}{c}\text { Modalidade } \\
\text { Ensino de Física }\end{array}$ & 61 & 50 & 0 \\
\hline $\begin{array}{c}\text { Modalidade } \\
\text { Química }\end{array}$ & 104 & 29 & 0 \\
\hline Total & 58 & 187 & 0 \\
\hline
\end{tabular}

Fonte: Adaptado de Biblioteca Digital de Teses e Dissertações da USP. Acesso em: 02 de maio 2017. 
Vale ressaltar que a nomenclatura Modalidade Ensino de Física e Modalidade Química dizem respeito aos trabalhos de Ensino de Física e Ensino de Química, respectivamente. Há essa diferenciação pois as áreas de conhecimento sofreram mudanças de nomenclatura ao longo dos anos.

Para saber o total de trabalhos defendidos no período de 2012 a 2016, fez-se uma busca avançada utilizando as ferramentas de busca ano e unidade, colocando os referidos anos e em unidades Interunidades em Ensino de Ciências. O Quadro 3 apresenta tais resultados.

Quadro 3 - Número de trabalhos defendidos nos anos de 2012 a 2016 no programa de Pós-Graduação Interunidades em Ensino de Ciências

\begin{tabular}{c|c}
\hline Ano & $\begin{array}{c}\text { Número de } \\
\text { trabalhos } \\
\text { defendidos }\end{array}$ \\
\hline 2012 & 36 \\
\hline 2013 & 47 \\
\hline 2014 & 39 \\
\hline 2015 & 56 \\
\hline 2016 & 42 \\
\hline Total & 220 \\
\hline
\end{tabular}

Fonte: Autoria própria (2017).

A fim de compreender quantos desses trabalhos defendidos envolvem discussões sobre a HC no Ensino, realizou-se uma busca avançada no site da biblioteca digital. Para a busca avançada utilizou-se como elementos de busca: ano de defesa, palavras-chave, resumo, título, unidade e área do conhecimento. Contudo, os elementos de busca: palavras-chave, resumo e título foram feitos separados, realizando-se assim três buscas em cada ano e área do conhecimento, utilizando como termo de busca a palavra história. No ano de defesa colocou-se de 2012 a 2016, Interunidades em Ensino de Ciências como unidade e alternou-se a área do conhecimento entre: Ensino de Biologia, Ensino de Física, Ensino de Química.

Após a realização desse levantamento inicial, foram encontrados um total de 47 trabalhos, sendo que 14 são referentes ao Ensino de Biologia, 25 ao Ensino de Física e oito referentes ao Ensino de Química.

A fim de evidenciar se os trabalhos encontrados nesse levantamento inicial estavam de fato relacionados à $\mathrm{HC}$, fez-se uma leitura do título, das palavraschaves e do resumo das teses e dissertações buscando os termos: História da Ciência, História e Filosofia da Ciência, História da Biologia, História da Física e História da Química.

Com essa análise, foi possível definir a amostra real desse trabalho, sendo esta composta por 23 trabalhos, em que sete se referem ao Ensino de Biologia, dez ao Ensino de Física e seis ao Ensino de Química.

As teses e dissertações que compõem a amostra foram organizadas de acordo com a categorização feita por Morais (2016) em sua pesquisa. O trabalho do autor supracitado consiste em uma dissertação de mestrado, em que, a fim de 
fundamentar o seu problema de pesquisa, realiza um Estado da Arte nos trabalhos publicados no "Encontro Nacional de Pesquisas em Educação em Ciências" (ENPEC) nos anos de 2009, 2011 e 2013, tendo como foco a HFC dentro do Ensino de Ciências, criando assim categorias para os trabalhos encontrados.

As autoras deste trabalho utilizaram essas categorias (a priori) para classificar as teses e dissertações selecionadas, com o intuito de identificar em quais perspectivas se encontram as pesquisas analisadas, contudo serão exibidas apenas as categorias identificadas na amostra dessa pesquisa.

Vale ressaltar aqui, que pelo fato das autoras entenderem que há diferenças entre os focos dos termos História da Ciência e História e Filosofia da Ciência, para este trabalho assumiu-se o termo História da Ciência. De acordo com Beltran, Saito e Trindade (2014, p.110) "[...] o foco da abordagem de história e filosofia da ciência no ensino encontra-se especialmente voltada ao fazer interno, à natureza da ciência, ligando-se, assim, mais enfaticamente à filosofia da ciência". Diferentemente,

A História da Ciência, desse modo, evita utilizar categorias gerais da filosofia da ciência para analisar e compreender o passado. Ao contrário, ela mesma procura elucidar que essas categorias foram formuladas posteriormente. Assim, embora a História da Ciência e a filosofia da ciência ocupem de temas comuns, elas, entretanto, não se confundem. Em linhas gerais, a filosofia da ciência busca regras gerais e universais, diferentemente da História da Ciência, que procura compreender o singular. Nesse sentido, a História da Ciência está mais preocupada com o devir, o que vem a ser, e não com o ser, isto é, com aquilo que supostamente deveria ser (BELTRAN; SAITO; TRINDADE, 2014, p.113).

Sendo assim, as categorias de Morais (2016) foram adaptadas. No Quadro 4 serão apresentadas as descrições das categorias que foram utilizadas neste trabalho.

Quadro 4 - Descrição das categorias referentes ao trabalho de Morais (2016)

\begin{tabular}{c|c|c}
\hline $\begin{array}{c}\text { Número } \\
\text { da } \\
\text { categoria }\end{array}$ & Categoria & Descrição da Categoria \\
\hline 1 & $\begin{array}{c}\text { História da Ciência } \\
\text { e a Formação de } \\
\text { Professores }\end{array}$ & $\begin{array}{c}\text { Analisar concepções acerca da História, Filosofia e } \\
\text { Natureza da Ciência; o efeito de cursos de História } \\
\text { da Ciência na formação; o uso de fontes primárias } \\
\text { no ensino superior e propostas didáticas; na } \\
\text { formação continuada procuraram explorar o uso e } \\
\text { efeito de cursos de História da Ciência na prática } \\
\text { docente. }\end{array}$ \\
\hline \multirow{2}{*}{3} & $\begin{array}{c}\text { História da Ciência } \\
\text { no Ensino de } \\
\text { Ciências }\end{array}$ & $\begin{array}{c}\text { Trabalhos que envolvam o uso de fontes primárias } \\
\text { de textos históricos e recursos teóricos para a } \\
\text { utilização da História da Ciência na Educação } \\
\text { Básica, presença da História da Ciência na }\end{array}$ \\
& $\begin{array}{c}\text { Educação Básica ou abordagens de conteúdo com } \\
\text { o uso da História da Ciência. }\end{array}$ \\
\hline $\begin{array}{c}\text { História da Ciência } \\
\text { nos Materiais } \\
\text { Didáticos }\end{array}$ & $\begin{array}{c}\text { Trabalhos que têm por objetivo o estudo } \\
\text { majoritário da História da Ciência no livro didático } \\
\text { das disciplinas abarcadas pelas ciências naturais } \\
\text { sejam em conteúdos específicos ou no material } \\
\text { como um todo. }\end{array}$ \\
\hline
\end{tabular}




\begin{tabular}{c|c|c}
\hline $\begin{array}{c}\text { Número } \\
\text { da } \\
\text { categoria }\end{array}$ & Categoria & Descrição da Categoria \\
\hline 4 & $\begin{array}{c}\text { Estudos históricos } \\
\text { de conteúdos e } \\
\text { personagens }\end{array}$ & $\begin{array}{c}\text { Trabalhos destinados ao estudo de personagens } \\
\text { específicos; ou pesquisas minuciosas sobre a } \\
\text { historicidade de determinado assunto. }\end{array}$ \\
\hline 5 & $\begin{array}{c}\text { Trabalhos teóricos- } \\
\text { filosóficos da }\end{array}$ & $\begin{array}{c}\text { Trabalhos que tenham como fio condutor } \\
\text { discussões filosóficas sobre a atividade científica e } \\
\text { fatores associadas a ela, tais como discussões de } \\
\text { gênero, discussões de Natureza da Ciência, o uso } \\
\text { de epistemologias no Ensino da Ciência e }\end{array}$ \\
\hline
\end{tabular}

Fonte: Adaptado de Morais (2016).

Dessa forma, no Quadro 5 estão apresentadas as informações das teses e dissertações que compõem a amostra deste trabalho, assim como as categorias que cada um se enquadra, a fim de melhor sistematizar os dados atribuiu-se apenas o número referente a cada uma das categorias citadas no Quadro 4.

Quadro 5 - Informações das teses e dissertações que compõem a amostra do trabalho suas respectivas categorias

\begin{tabular}{|c|c|c|c|c|}
\hline Ano & Modalidade & Natureza & Autor & Categoria \\
\hline \multirow{4}{*}{2012} & \multirow{2}{*}{ Ensino de Física } & Dissertação & ALBUQUERQUE & 2 \\
\hline & & Tese & MOURA & 1 \\
\hline & \multirow{2}{*}{ Ensino de Química } & Dissertação & $\mathrm{BUCl}$ & 4 \\
\hline & & Tese & MARTORANO & 1 \\
\hline \multirow{7}{*}{2013} & \multirow{3}{*}{ Ensino de Física } & \multirow{2}{*}{ Dissertação } & LAGO & 2 \\
\hline & & & SOUZA-LOPES & 2 \\
\hline & & Tese & SILVA & 2 \\
\hline & \multirow{4}{*}{ Ensino de Biologia } & \multirow{4}{*}{ Dissertação } & BITTENCOURT & 3 \\
\hline & & & CARVALHO & 4 \\
\hline & & & SIÃO & 4 \\
\hline & & & SILVA & 2 \\
\hline \multirow{5}{*}{2014} & \multirow{3}{*}{ Ensino de Física } & \multirow{2}{*}{ Dissertação } & NORONHA & 5 \\
\hline & & & SKOLIMOSKI & 2 \\
\hline & & Tese & CAMPOS & $*$ \\
\hline & \multirow{2}{*}{ Ensino de Biologia } & \multirow{2}{*}{ Dissertação } & SOUZA & 2 \\
\hline & & & JESUS & 2 \\
\hline \multirow{5}{*}{2015} & Ensino de Física & Tese & BAGDONAS & 2 \\
\hline & \multirow{3}{*}{ Ensino de Química } & \multirow{2}{*}{ Dissertação } & GOMES & 2 \\
\hline & & & HIRAYAMA & 1 \\
\hline & & Tese & BALDINATO & 4 \\
\hline & Ensino de Biologia & Dissertação & BRUNELLI & 2 \\
\hline \multirow{2}{*}{2016} & Ensino de Física & Tese & SCHMIEDECKE & 1 \\
\hline & Ensino de Química & Dissertação & PULIDO & 3 \\
\hline
\end{tabular}

Fonte: Autoria própria (2017). 


\section{RESULTADOS E DISCUSSÃO}

Como mencionado anteriormente, o levantamento possibilitou a seleção de 23 trabalhos (referentes a teses e dissertações), os quais foram categorizados de acordo com o trabalho de Morais (2016). Neste momento, busca-se a partir de uma análise mais profunda, traçar um panorama geral das teses e dissertações que envolvem a HC e o Ensino de Ciências, defendidas entre 2012 e 2016, no Programa de Pós-Graduação Interunidades em Ensino de Ciências da USP. Primeiramente, serão apresentadas análises quantitativas dos dados e, em seguida, uma discussão por categorias, dos focos dos trabalhos presentes nelas.

A partir dos resultados das buscas, tem-se que a HC está presente em aproximadamente $10 \%$ dos trabalhos defendidos no Programa, de 2012 a 2016. Além disso, constatou-se que a linha de pesquisa História, Filosofia e Cultura no Ensino de Ciências se faz presente no referido programa e conta com a presença de 16 docentes.

No que diz respeito às categorias aqui utilizadas, têm-se que quase metade dos trabalhos (11 de 23) se enquadram na categoria 2 - História da Ciência no Ensino de Ciências, a qual compreende pesquisas realizadas no âmbito da Educação Básica. Além disso, essa categoria abarca trabalhos que desenvolvem propostas em sala de aula, evidenciando a abordagem da $\mathrm{HC}$ nesse nível de ensino.

Acerca dos trabalhos em si, um deles não se enquadrou nas categorias utilizadas pelas autoras. O mesmo busca investigar como o processo de compreensão do princípio de conservação de energia mecânica se dá em diferentes níveis de ensino. Campos (2014) conduz a pesquisa tanto no nível médio quanto superior, e utiliza a $\mathrm{HC}$ para apresentar o conceito de Energia. Uma vez que a pesquisa ocorreu nos dois níveis de ensino, o trabalho não se encaixa em apenas uma categoria.

Categoria 1 - História da Ciência e a Formação de Professores

Para essa categoria, a qual contempla trabalhos que de alguma forma tem relação entre a $\mathrm{HC}$ e a formação de professores, seja ela inicial ou continuada, têmse aqui a presença de quatro trabalhos, sendo dois relacionados ao Ensino de Física e dois ao Ensino de Química.

Os dois trabalhos relacionados ao Ensino de Física, apresentam um foco em comum, buscam utilizar uma abordagem envolvendo a $\mathrm{HC}$ a fim de promover a formação de professores críticos, que saibam discutir sobre uma Ciência mais humanizada, não linear. A tese de Moura (2012) busca por meio de uma Abordagem Multicontextual da História da Ciência (AMHIC) uma formação críticotransformadora, já a tese de Schmiedecke (2016) busca uma formação crítica por meio da Moderna Historiografia da Ciência. Ambos os trabalhos contribuem para a área de Ensino de Ciências no que tange a preocupação com os modelos que vem sendo discutidos para a formação de professores, sendo este o modelo do professor como intelectual crítico (GIROUX, 1997), assim a presença de pesquisas com essa abordagem, auxiliam as discussões para a consolidação de tal modelo.

Já os trabalhos relacionados ao Ensino de Química divergem do foco dos trabalhos citados acima. Tem-se a presença da tese da Martorano (2012), cujo foco 
está relacionado a um curso de formação continuada sobre a Cinética Química, em que a abordagem escolhida para trabalhar o conceito químico é a HC. A autora constrói um desenvolvimento histórico do tema, que é utilizado posteriormente no curso, e busca identificar se a HC pode contribuir para a transição progressiva dos professores sobre esse conceito. A HC é alvo de críticas em relação à dificuldade de sua inserção na formação inicial. Dessa forma, muitos professores não tiveram contato com tal abordagem, sendo assim, proporcionar cursos de formação continuada que possibilitem o contato do professor com tais discussões significa um avanço para a área e consequentemente para a formação do professor em exercício.

Por fim, ainda relacionada ao Ensino de Química, tem-se a dissertação de Hirayama (2015), a qual tem como foco a investigação sobre a concepção que os professores de química têm a respeito da inserção da $\mathrm{HC}$ no ensino. $\mathrm{O}$ autor apresenta discussões sobre a HC, Natureza da Ciência, Filosofia da Química, a fim de subsidiar suas análises. As autoras deste trabalho enfatizam a importância da pesquisa supracitada no que diz respeito ao entendimento de como os professores compreendem a inserção da $\mathrm{HC}$, pois uma das dificuldades encontradas para sua inclusão ao Ensino Ciências é a falta de conhecimento adequado dos professores sobre HC.

\section{Categoria 2 - História da Ciência no Ensino de Ciências}

No que diz respeito a essa categoria foram selecionados 11 trabalhos, ou seja, é a categoria com o maior número de trabalhos. Nela são enquadrados todos os trabalhos que se referem ao uso da HC na Educação Básica.

Seis pesquisas estão relacionadas ao Ensino de Física, são os trabalhos de Albuquerque (2012), Lago (2013), Souza-Lopes (2013), Silva, D. N. (2013), Skolimoski (2014) e Bagdonas (2015). Quatro trabalhos foram desenvolvidos no campo do Ensino de Biologia, são eles, Silva, T. T. (2013), Souza (2014), Jesus (2014) e Brunelli (2015). Já no campo do Ensino de Química, apenas um trabalho se refere a essa categoria, é a pesquisa de Gomes (2015).

Após a leitura dos resumos, percebeu-se que as pesquisas de Albuquerque (2012), Lago (2013), Bagdonas (2015), Jesus (2014), Souza (2014) e Silva, T. T. (2013) envolveram a elaboração e a utilização de sequências didáticas no Ensino Fundamental ou Médio. Esses autores fizeram pesquisas em fontes primárias e secundárias sobre o tema específico de cada sequência didática, os trabalhos possuem trechos ou capítulos inteiramente dedicados a apresentação desses materiais de HC. Percebe-se que esses trabalhos, de modo geral, trazem duas grandes contribuições, pois podem auxiliar professores, alunos e pesquisadores a entender determinados conteúdos ou episódios históricos, além de permitir a compreensão de especificidades da inserção da HC através dos resultados da utilização das sequências didáticas em situações reais de ensino.

Os trabalhos de Souza-Lopes (2013), Gomes (2015) e Brunelli (2015) também realizaram pesquisas envolvendo o resgate de episódios e conteúdos históricos. Os autores apresentam detalhadamente propostas de sequências didáticas que poderão ser utilizadas por professores da Educação Básica. Diferentemente dos trabalhos citados anteriormente, esses não chegaram a desenvolver propostas em sala de aula. 
Já os trabalhos de Silva, D. N. (2013) e de Skolimoski (2014) se referem a pesquisas relacionados ao levantamento de concepções de alunos sobre temas específicos da Física, divergindo assim da maioria dos trabalhos levantados nessa categoria, pois esses se debruçam a estudar possibilidades de desenvolvimento de propostas didáticas nas aulas de ciências.

Silva, D. N. (2013) realizou uma pesquisa para compreender e mapear as dificuldades de estudantes do Ensino Médio e do curso de Licenciatura em Física em empregar corretamente concepções científicas em questões que se referem a fenômenos termodinâmicos. Esse trabalho envolveu a aplicação de questionários em turmas de diferentes níveis de ensino e apresenta suas análises dialogando com episódios históricos que podem estar relacionados com algumas concepções alternativas que os estudantes carregam.

Skolimoski (2014) buscou em sua pesquisa compreender quais são as possibilidades e dificuldades de trabalhar a cosmologia no Ensino Médio. Para tanto, a autora realizou uma pesquisa teórica sobre os mitos e os aspectos históricos do assunto e na sequência entrevistou professores de Física da Educação Básica em exercício. Esse trabalho fornece importantes subsídios para futuros estudos sobre a inserção da cosmologia no Ensino Médio.

\section{Categoria 3 - História da Ciência nos Materiais Didáticos}

A categoria 3 abrange trabalhos cujo objetivo principal é a análise da $\mathrm{HC}$ em livros didáticos, seja de conteúdos específicos ou do material completo. Verificouse que dois trabalhos se referem a essa categoria.

O trabalho de Bittencourt (2013) trata-se de uma pesquisa desenvolvida no campo da Biologia, onde foram analisados os nove livros didáticos de Biologia recomendados pelo Plano Nacional do Livro Didático para o Ensino Médio (PNLEM) no ano de 2007, na análise o pesquisador investigou a abordagem dada às contribuições de Gregor Mendel personagem importante para a História da Genética. Além disso, a pesquisa buscou fornecer um material histórico de apoio ao professor que optar por trabalhar com esse episódio em suas aulas. $\mathrm{O}$ autor fez análise de fontes primárias à luz de fontes secundárias.

O trabalho de Pulido (2016) compreende uma investigação na área de Química, o autor também fez um resgate histórico, pesquisando em fontes primárias e secundárias, à luz da epistemologia de Canguilhem e de referenciais contemporâneos da historiografia da ciência, construindo um estudo de caso para caracterizar a teoria dualista de Berzelius e sua relevância no contexto original e na atualidade. Na sequência o autor analisa os quatro livros didáticos de Química, recomendados pelo PNLEM de 2015, buscando identificar a presença de termos e conceitos que remetem a tal teoria. Há presença de termos dessa teoria em três dos livros analisados, dessa forma o autor faz uma discussão sobre as implicações dessa constatação para o Ensino de Química.

\section{Categoria 4 - Estudos históricos de conteúdos e personagens}

Aqui encontram-se aqueles trabalhos cujo foco principal é o estudo de um personagem ou tema específico. Quatro foram os trabalhos vinculados a essa 
categoria, sendo que a maioria deles defendem sua colaboração para a área de Ensino ao contribuírem no que diz respeito à formação de professores. Isso porque tais trabalhos se tornam fonte de informação para que os professores compreendam como determinado conceito/conteúdo vem sendo desenvolvido ao longo da história.

Três dos trabalhos aqui categorizados utilizam de episódios históricos em sua pesquisa. São eles: Buci (2012), Carvalho (2013) e Baldinato (2015). Buci (2012) defende que a HC tem sua importância ao auxiliar o aluno na compreensão de como se dá o conhecimento científico. Carvalho (2013) afirma que o uso de episódios históricos que emergem a partir de controvérsias no ensino pode auxiliar na distorção da ideia de uma ciência única, pautada no método científico. Baldinato (2015) relaciona seu trabalho com o ensino pelo fato de possibilitar aos professores maior contato com as obras de divulgação do passado.

O último trabalho dessa categoria, Sião (2013), objetivou compreender a importância da parceria de cientistas para o desenvolvimento da genética no Brasil e também se o estudo de genética de populações drosófilas deveria ser abordado na Educação Básica.

\section{Categoria 5 - Trabalhos teóricos-filosóficos da História da Ciência}

Nesta categoria estão alocados os trabalhos que têm como foco discussões filosóficas, sobre Natureza da Ciência, ou o uso de epistemologias no Ensino de Ciências ou ainda enfoques históricos para a compreensão da Ciência. Dessa forma, o levantamento indicou a presença de apenas uma dissertação, sendo esta referente ao trabalho de Noronha (2014), o qual envolve a área de conhecimento em Ensino de Física.

Essa pesquisa tem como objetivo principal a investigação de quais são os principais aspectos da Natureza da Ciência, relacionado ao debate entre o realismo e o antirrealismo científico, que emergem da história e filosofia da teoria da relatividade espacial. Com isso, apontam a $\mathrm{HC}$ como uma abordagem que possibilita tais discussões, de forma a abordar uma ciência mais crítica. Trabalha ainda com uma construção histórica do realismo e do antirrealismo.

\section{CONSIDERAÇÕES FINAIS}

Esta pesquisa visa apresentar um panorama no que diz respeito à aproximação da HC no Ensino de Ciências a partir de um levantamento das teses e dissertações defendidas no Programa de Pós-Graduação Interunidades em Ensino de Ciências entre os anos de 2012 e 2016. Diante das informações obtidas na Biblioteca Digital de Teses e Dissertações da USP, constatou-se que nesse período foram defendidos 220 trabalhos nas áreas de Física, Química e Biologia. Ao utilizar a ferramenta de busca avançada da Biblioteca com a palavra descritora "história", foram encontrados 47 trabalhos, cujos resumos foram lidos a fim de selecionar os trabalhos referentes à HC. Constatou-se que apenas 23 trabalhos tratavam dessa temática.

Desses trabalhos, 10 estão relacionados ao Ensino de Física, 7 ao Ensino de Biologia e 6 ao Ensino de Química. No Quadro 4, as autoras apresentam algumas 
informações gerais referentes a esses trabalhos. Após a leitura dos resumos das pesquisas, baseou-se no trabalho de Morais (2016) para organizar as teses e dissertações. Utilizou-se as seguintes categorias: História da Ciência e a Formação de Professores; História da Ciência no Ensino de Ciências; História da Ciência nos Materiais Didáticos; Estudos históricos de conteúdos e personagens e Trabalhos teóricos-filosóficos da História da Ciência.

Constatou-se que 11 trabalhos se referem à categoria 2 (História da Ciência no Ensino de Ciências). Essas pesquisas foram desenvolvidas no campo da Educação Básica, e em sua maioria envolveram a elaboração e desenvolvimento de sequências didáticas utilizando a HC. Sendo assim, é possível entender que há uma grande preocupação com pesquisas que envolvam a Educação Básica.

A partir desse levantamento pode se inferir que há necessidade de ampliar as pesquisas que abordam a temática da $\mathrm{HC}$, devido ao fato de diversos trabalhos apontarem que a sua utilização na prática docente auxilia em uma visão de Ciência mais adequada, possibilitando questionamentos e a não aceitação desta como uma verdade absoluta, contribuindo para a formação de estudantes críticos.

Por fim, espera-se que o trabalho contribua para estudos sobre a HC e onsino de Ciências, pois apresenta um delineamento inicial sobre as tendências de pesquisa sobre essa temática em um Programa de Pós-Graduação de elevada importância no contexto brasileiro. 


\title{
A survey of theses and dissertations from a graduate program on the approach of History of Science and Science Teaching
}

\begin{abstract}
Considering the importance of the approach of History of Science (HS) and Science Teaching, in this work, the authors aimed to elaborate a panorama of theses and dissertations produced in the Inter-units in Teaching of Sciences Graduate Program - University of São Paulo, from 2012 to 2016 that approach HS and Science Teaching. A search was made at the Digital Library of Theses and Dissertations of the University of São Paulo, seeking to highlight the total number of papers defended in the program since its implementation and in relation to the years of 2012 to 2016 . It was found 220 works defended during the years mentioned before, being 23 of them researches involving the approach of HS and Science Teaching. In order to identify the HS perspectives used by such works, the authors pointed out the objectives and focuses of the selected theses and dissertations. It was found five categories works, using the categories proposed by Morais (2016), being History of Science in Science Teaching the most significant one in numbers of researches. With the completion of this survey, it is noted the need to give attention to works that deal with HS, due to the fact that its use in teaching helps the students to have a more adequate idea of Science, allowing questionings about it and granting the non-acceptance of Science as an absolute truth.
\end{abstract}

KEYWORDS: History of Science. Survey. Theses and Dissertations. Science teaching. 


\section{AGRADECIMENTOS}

Capes - Coordenação de Aperfeiçoamento de Pessoal de Nível Superior.

\section{NOTAS}

1 De acordo com Romanowsk e Ens (2006), esse tipo de estudo objetiva a sistematização da produção numa determinada área do conhecimento. Quando o levantamento aborda apenas um setor das publicações sobre o tema estudado é denominado de "estado do conhecimento". E em situações onde são consultadas todas as fontes de dados sobre determinado assunto, chamamos de "estado da arte".

2 Disponível em: <http://www.teses.usp.br/> Acesso em: 27 abril 2017.

3 As informações foram obtidas na página do Programa. Disponível em: <http://portal.if.usp.br/cpgi/> Acesso em: 29 abril 2017.

\section{REFERÊNCIAS}

ALBUQUERQUE, V. O caso Plutão e a natureza da ciência: uma proposta para alunos do ensino médio. 2012. 205 f. Dissertação (Mestrado) - Programa de PósGraduação Interunidades em Ensino de Ciências, Universidade de São Paulo, 2012.

BAGDONAS, A. Controvérsias envolvendo a natureza da ciência em sequências didáticas sobre cosmologia. 2015. 266 f. Tese (Doutorado em Ensino de Física) Ensino de Ciências (Física, Química e Biologia), Universidade de São Paulo, São Paulo, 2015.

BALDINATO, J. O. Conhecendo a química: um estudo sobre obras de divulgação do início do século XIX. 2015. 169 p. Tese de Doutorado. Universidade de São Paulo.

BELTRAN, M. H. R. História da Química e Ensino: estabelecendo interfaces entre campos interdisciplinares. Abákos, v.1, n.2, p. 67-77, 2013. Disponível em: <http://periodicos.pucminas.br/index.php/abakos/article/view/P.23169451.2013v1n2p67/5324>. Acesso em: 27 abr. 2017.

BELTRAN, M. H. R.; SAITO, F.; TRINDADE, L. S. P. História da Ciência para formação de professores. São Paulo: Editora Livraria da Física, 2014, 128 p.

BITTENCOURT, F. B. O tratamento dado à história da biologia nos livros didáticos brasileiros recomendados pelo PNLEM-2007: análise das contribuições 
Instituto de Química, Instituto de Biociências, Faculdade de Educação, Universidade de São Paulo, São Paulo, 2013.

BRUNELLI, A. O desenvolvimento do conceito de linkage (1902-1915): uma contribuição histórica para o ensino de genética. 2015. 76 f. Dissertação (Mestrado) - Instituto de Física, Instituto de Química, Instituto de Biociências, Faculdade de Educação, Universidade de São Paulo, São Paulo, 2015.

$\mathrm{BUCl}$, J. R. Humphry Davy e a questão da classificação do potássio e do sódio.2012. 103 p. Tese de Doutorado. Universidade de São Paulo.

CAMPOS, A. A conceitualização do Princípio de Conservação de Energia Mecânica, os processos de aprendizagem e a Teoria dos Campos Conceituais. 2014. 522 f. 2014. Tese de Doutorado. Tese (Doutorado em Educação) Faculdade de Educação, Universidade de São Paulo, São Paulo, 2014.

CARVALHO, E. C. A controvérsia sobre a geração espontânea entre Needham e Spallanzani: Implicações para o ensino de Biologia. 2013. 138 p. Tese de Doutorado. Universidade de São Paulo.

GIL-PÉREZ, D.; MONTORO, I. F.; ALÍS, J. C.; CACHAPUZ, A.; PRAIA, J. Para uma imagem não deformada do trabalho científico. Ciência \& educação, Bauru, SP, v. 7, n. 2, 2001. Disponível em: <http://www.scielo.br/pdf/ciedu/v7n2/01.pdf>. Acesso em: 27 abr. 2017.

GIROUX, H. A. Os professores como intelectuais: rumo a uma pedagogia crítica da aprendizagem. Porto Alegre: Artes Médicas, 1997. 270p.

GOMES, T. G. Uma história da radioatividade para a Escola Básica: desafios e propostas. 2015. 99 f. Dissertação (Mestrado) - Instituto de Física, Instituto de Química, Instituto de Biociências, Faculdade de Educação, Universidade de São Paulo, São Paulo, 2015.

HIRAYAMA, M. P. As concepções de professores de química sobre a utilização de elementos da história e filosofia da ciência no ensino. 2015. 317 f. Dissertação de Mestrado - Instituto de Física, Instituto de Química, Instituto de Biociências e Faculdade de educação - Programa Interunidades em Ensino de Ciências, Universidade de São Paulo, São Paulo, 2015.

JESUS, L. R. Ensinando o Sistema Circulatório no Ensino Fundamental. 2014. 133 f. Dissertação (Mestrado). Programa Interunidades em Ensino de Ciências, 
KRASILCHIK, M. Reformas e realidade: o caso do ensino de ciências. São Paulo em Perspectiva, v.14, n.1, p. 85-93, 2000. Disponível em:

<http://www.scielo.br/pdf/spp/v14n1/9805.pdf>. Acesso em: 28 abr. 2017.

LAGO, L. G. Lua: fases e facetas de um conceito. 2013. 202 f. Dissertação (mestrado) - Instituto de Física e Faculdade de Educação, Universidade de São Paulo, São Paulo, 2013.

MARTORANO, S. A. A. A transição progressiva dos modelos de ensino sobre cinética química a partir do desenvolvimento histórico do tema. 2012. $360 \mathrm{f}$. Tese (Doutorado em Ensino de Ciências) - Faculdade de Educação, Instituto de Física, Instituto de Química e Instituto de Biociências - Programa Interunidades em Ensino de Ciências, Universidade de São Paulo, São Paulo, 2012.

MATTHEWS, M. R. História, Filosofia e Ensino de Ciências: a tendência atual de reaproximação. Caderno Catarinense de Ensino de Física, v. 12, n. 3, p. 164-214, 1995.

MORAIS, W. R. História e Natureza da Ciência no Ensino de Biologia: perfil e concepções de professores em serviço e de materiais didáticos. 2016. 230 f. Dissertação (Mestrado em Educação para a Ciência) - Universidade Estadual Paulista "Júlio de Mesquita Filho" - Campus Bauru, Bauru, 2016.

MOURA, B. A. Formação crítico-transformadora de professores de Física: uma proposta a partir da História da Ciência. 2012. 308 f. Tese (doutorado) Faculdade de Educação, Instituto de Física, Instituto de Química e Instituto de Biociências - Programa Interunidades em Ensino de Ciências, Universidade de são Paulo, São Paulo, 2012.

NARDI, R. A área de ensino de ciências no Brasil: fatores que determinaram sua constituição e suas características segundo pesquisadores brasileiros. 2005. $170 f$. Tese (Livre- Docência) - Faculdade de Ciências, Universidade Estadual Paulista, Bauru, 2005.

NORONHA, A. Interpretando a Relatividade Especial: Discutindo o Debate Realismo e Antirrealismo Científicos no Ensino de Ciências. 2014. 245 f. Dissertação (Mestrado em Ensino de Física) -Faculdade de Educação, Instituto de Física, Instituto de Química e Instituto de Biociências - Programa Interunidades em Ensino de Ciências, Universidade de São Paulo, São Paulo, 2014.

PULIDO, M. D. O dualismo eletroquímico de Berzelius: sua caracterização e presença em livros didáticos de química. 2016. 163 f. Dissertação (Mestrado). Programa Interunidades em Ensino de Ciências, Universidade de São Paulo, São Paulo, 2016. 
ROMANOWSKI, J. P.; ENS, R. T. As pesquisas denominadas do tipo "estado da arte" em educação. Diálogo Educacional, v. 6, n. 19, p. 37-50, set./dez., 2006.

SANTOS, W. P.; MORTIMER, E. F. Uma Análise de Pressupostos Teóricos da Abordagem C-T-S (Ciência - Tecnologia - Sociedade) no Contexto da Educação Brasileira. Ensaio - Pesquisa em Educação em Ciências, v.2, n.2, p. 133-162, 2002. Disponível em: <http://www.scielo.br/pdf/epec/v2n2/1983-2117-epec-2-0200110.pdf>. Acesso em: 28 abr. 2017.

SCHMIEDECKE, W. G. A história da ciência nacional na formação e na prática de professores de Física. 2016. 246 f. Tese (Doutorado) - Faculdade de Educação, Instituto de Física, Instituto de Química e Instituto de Biociências - Programa Interunidades em Ensino de Ciências, Universidade de São Paulo, São Paulo, 2016.

SIÃO, J. F. M. Os estudos com drosófilas no Instituto de Biociências da USP nas décadas de 1940 e 1950: entrevistas com docentes. 2015. 184 p. Tese de Doutorado. Universidade de São Paulo.

SILVA, D. N. Ensino e aprendizagem da Termodinâmica: questões didáticas e contribuições da história da ciência. 2013. 250 f. Tese (Doutorado). Instituto de Física e Faculdade de Educação, Universidade de São Paulo, São Paulo, 2013.

SILVA, T. T. Darwin na sala de aula: replicação de experimentos históricos para auxiliar a compreensão da teoria evolutiva. 2013.172 f. Dissertação (Mestrado) Programa de Pós-Graduação Interunidades em Ensino de Ciências, Universidade de São Paulo, São Paulo, 2013.

SKOLIMOSKI, K. N. Cosmologia na teoria e na prática: possibilidades e limitações no ensino. 2014. $251 \mathrm{f}$. Instituto de Física, Instituto de Química, Instituto de Biociências, Faculdade de Educação - Programa Interunidades em Ensino de Ciências, Universidade de São Paulo, 2014.

SOUZA, R. A. L. A viagem de Alfred Russel Wallace ao Brasil: uma aplicação de história da ciência no ensino de Biologia. 2014. 375f. Dissertação (Mestrado)Programa de Pós-Graduação Interunidades em Ensino de Ciências, Universidade de São Paulo, São Paulo, 2014.

SOUZA-LOPES, E. "E o elétron? É onda ou é partícula?" Uma proposta para promover a ocorrência da Alfabetização Científica de Física Moderna e Contemporânea em estudantes do Ensino Médio. 2013. 251 f. Dissertação (mestrado) - Instituto de Física e Faculdade de Educação da Universidade de São Paulo (IFUSP e FEUSP). 
Recebido: 29 mai. 2017

Aprovado: 29 ago. 2017

DOI: $10.3895 /$ actio.v2n1.6788

Como citar:

PALMA, L. C. R.; GUARNIERI, P. V.; PANSERA, F. C.; GATTI, S. R. T. Um levantamento de teses e

dissertações de um programa de pós-graduação sobre a aproximação da História da Ciência e o Ensino de Ciências. ACTIO, Curitiba, v. 2, n. 1, p. 401-419, jan./jul. 2017. Disponível em:

$<$ https://periodicos.utfpr.edu.br/actio>. Acesso em: XXX.

\section{Correspondência:}

Lorena Cristina Romero Palma

Rua Wladimir Gatti, 467. CEP: 86605-280. Rolândia, Paraná, Brasil.

Direito autoral: Este artigo está licenciado sob os termos da Licença CreativeCommons-Atribuição 4.0

Internacional.

(c) (1) 